\title{
Delayed Transfer of Immune Cells or the Art of Donor Lymphocyte Infusion
}

\author{
J. H. Frederik Falkenburg, Christoph Schmid, \\ Hans Joachim Kolb, Franco Locatelli, \\ and Jürgen Kuball
}

\subsection{Biology of Donor Lymphocyte Infusion (DLI)}

\subsubsection{Diversity of Lymphocyte Subsets Used for DLI}

In the context of an allogeneic HSCT, the interplay between host and donor immune cells is considered to be the primary mechanism responsible for graft-versus-leukemia (GVL) reactivity and also able to mediate GVHD (Kolb et al. 2004). The tissue specificity of the immune response determines the balance between GVL and GVHD, as well as tropism of GVHD. The main population for success and failure of HSCT and DLIs originates from $\alpha \beta$ T cells. However, other subsets are also key modulators of efficacy, e.g., NK cells most likely provide acute control of leukemia and of infections like
CMV. However, NK cells become rapidly educated over time (Orr and Lanier 2010) and lose their antileukemia activity. Other subsets, like $\gamma \delta \mathrm{T}$ cells, appear to have a more prolonged antileukemia effect (Handgretinger and Schilbach 2018) and are also helpful in controlling CMV reactivation (Scheper et al. 2013; de Witte et al. 2018). NKT cells, like regulatory $T$ cells, have been mainly reported to influence GVHD effects. While an increase in NKT cells in the graft associates with a reduced GVHD incidence (Malard et al. 2016), depletion of T regulatory $\mathrm{T}$ cells in DLI improves GVL effects, although it augments the risk of GVHD (Maury et al. 2010). Thus, lymphocyte infusions as part of the graft at the time of transplantation, or delayed as DLI, have multiple effector cells that need to be considered in terms of different alloreactive effects.
J. H. Frederik Falkenburg

Department of Hematology,

Leiden University Medical Center, Leiden, The

Netherlands

C. Schmid

Klinikum Augsburg, University of Munich,

Munich, Germany

\section{H. J. Kolb}

Department of Hematology-Oncology Immunology Infectious Diseases, Klinikum München-Schwabing, Munich, Germany

\section{F. Locatelli}

Department of Pediatric Hematology and Oncology, IRCCS Bambino Gesù Children's Hospital, Rome, Italy

Department of Pediatric Science, University of Pavia, Pavia, Italy

J. Kuball $(\bowtie)$

Department of Hematology, UMC, Utrecht, The Netherlands

Laboratory of Translational Immunology,

UMC, Utrecht, The Netherlands

e-mail: J.H.E.Kuball@umcutrecht.nl 


\subsubsection{Naïve $\alpha \beta T$ Cell: Host Dendritic Cell (DC) Interaction as a Key Driver of Immune Response}

Since in the context of HLA-matched transplantation, most alloreactive $\alpha \beta \mathrm{T}$ cells are present within the naïve repertoire of the donor, recipientderived dendritic cells (DC) play an essential role in provoking the $\alpha \beta T$ cell immune response (Stenger et al. 2012). DC are key players in provoking appropriate $\mathrm{T}$ cell activation, and because DC are derived from the hematopoietic system, an immune response of donor origin targeting DC from the recipient will likely result in an immune response against recipient hematopoietic cells, including the malignant population, and therefore give rise to GVL. The level of cross-reactivity against antigens broadly expressed on non-hematopoietic cells will determine the likelihood and severity of GVHD. DCs are present in the lympho-hematopoietic system but also with relatively high frequencies in the target tissues of GVHD. At the time of transplant, all DCs are of recipient origin. When activated by danger signals provoked by tissue damage and pathogens, DCs will present endogenous antigens, as well as cross-present antigens derived from the non-hematopoietic tissues and pathogens. Therefore, in T-cell-replete HSCT, it is difficult to dissect the GVL and GVHD effects (Boelens et al. 2018; Admiraal et al. 2017).

Consequently, many current transplantation techniques deplete immune cells from the graft and administer DLIs at later time points as standard part of the transplantation regimen. Both a complete immune depletion by selection of CD34positive stem cells (Pasquini et al. 2012) and partial depletion of alloreactive T-cells through PT-CY (Mielcarek et al. 2016) are used. This upfront T-cell depletion associates with a lower risk of GVHD and allows very early DLIs for the majority of patients (e.g., 100 days after HSCT) and an improved segregation of GVL and GVHD effects. More recent transplantation strategies better consider the sophisticated variety of immune cells. These novel strategies utilize either a selective depletion of $\alpha \beta$ T cell (Locatelli et al. 2017) or naïve subsets (Bleakley et al. 2015) to abrogate GVHD, while maintaining early immune surveillance directed against infections as well as leukemia.

\subsubsection{Diversity of Immune Repertoires and Potential Impact on Interventions}

After HSCT, the $\alpha \beta$ and $\gamma \delta$ TCR repertoire is reconstituted out of the graft of the donor, which contains in T-cell-replete transplantations between $5 \times 10^{7}$ and $1 \times 10^{9} \mathrm{~T}$ cells/kg (Czerw et al. 2016). Of the T cells, the $\gamma \delta \mathrm{T}$ cells are the first to reach normal numbers, followed by the CD $8+\alpha \beta$ T cells and finally the CD $4+\alpha \beta$ T cells which do not reach normal levels within the first year after HSCT (Kanakry et al. 2016). It is important to note that numerical reconstitution of the $\mathrm{T}$ cells does not mean that the diversity of the repertoire is already normalized, reflected by the clinical observations that patients are highly vulnerable to many infections for years after HSCT. (van Heijst et al. 2013; Ravens et al. 2017).

Factors that influence the T-cell repertoire reconstitution after HSCT include the source of the graft and occurrence of infectious challenges such as CMV and EBV, GVHD, and cellular interventions such as DLI. The repertoire of $\alpha \beta T$ cells after HSCT has been studied extensively in different HSCT settings. Six months after HSCT, the $\alpha \beta T C R$ repertoire is still very restricted when compared to that of healthy individuals. A cord blood graft leads to a greater diversity of the $\alpha \beta$ TCR repertoire at 6 and 12 months, compared to other graft sources (van Heijst et al. 2013). Even 2-5 years after HSCT, the repertoire is still not as diverse as in healthy individuals (Kanakry et al. 2016; van Heijst et al. 2013). CMV reactivation shapes the repertoire in such a way that a marked contraction of the diversity is observed (Kanakry et al. 2016; van Heijst et al. 2013; Suessmuth et al. 2015). GVHD has been associated with both an increased (van Heijst et al. 2013) and a decreased diversity (Yew et al. 2015). We favor the hypothesis that selective GVL reactivity is associated with lower diversity, lower magnitude, and relatively tissue-specific recognition of hematopoiesis by alloreactive $\alpha \beta \mathrm{T}$ cells 
(van Bergen et al. 2017). Less is known about the diversity of the $\gamma \delta$ TCR repertoire after HSCT. The repertoire of the $\gamma \delta \mathrm{T}$ cells seems to be established quite early, at 30-60 days after HSCT. CMV reactivation promotes a massive expansion of a few $\gamma \delta \mathrm{T}$ cell clonotypes (mainly belonging to the $\delta 1$ subset), which leads to a so-called repertoire focusing (Ravens et al. 2017). Within this context, it is reasonable to argue that the administration of a DLI might in the future depend not only on the type of the disease or timing but also on the size of the $\alpha \beta$ and $\gamma \delta$ T cell repertoire observed at a given time point.

\subsection{Guidelines for Prophylactic and Preemptive DLI as Well as DLI After Relapse}

\subsubsection{General Considerations}

Currently, neither the diversity of the TCR repertoire nor the infusion of subsets of lymphocytes is used to guide or fine-tune the intervention DLI in daily practice. To prevent relapse of the underlying disease, timing and dosing of non-manipulated DLI after HSCT can be used to relatively skew the immune response toward GVL reactivity, as tissue damage after transplantation is gradually repaired and the donors' DCs steadily replace the recipients' DCs within the first 6 months after HSCT. Therefore, the magnitude and diversity of the interplay between host and donor immune subsets will progressively diminish. This is evidenced by the clinical observation that when the interval between HSCT and the infusion of DLI increases, the total number of $\alpha \beta T$ cells that can be administered without induction of severe GVHD will increase from less than $10^{5} / \mathrm{kg}$ after 3 months, to more than $10^{6} / \mathrm{kg}$ at 6 months (Table 59.1) (Yun and Waller 2013). Main prerequisite at the time of DLI is therefore also the absence of tissue damage and inflammatory circumstances, thus a lack of GVHD and uncontrolled infections.

\subsubsection{Timing, Dosing, and Frequency of DLI}

The following recommendations refer to the infusion of non-manipulated donor cells after no or in vivo T-cell-depleted transplantation from matched sibling or unrelated donors in patients with acute leukemia or MDS, which is the most frequently studied scenario. Further aspects, which may modify these recommendations, are discussed below. With respect to the indication of DLI for prevention of overt hematological relapse, two situations are distinguished. Furthermore, DLIs can be given within the context for overt relapses.

\subsubsection{Prophylactic DLI}

A prophylactic DLI is applied in patients with a high-risk of relapse, but at a stage when there is no evidence of the underlying disease. Usually, prophylactic DLIs are given starting from day +90 or +100 after HSCT, provided that the patient is off IS and free of GVHD for about 1 month. $\mathrm{CD} 3+$ doses used for the first infusion depend on donor type and timing and vary between $1 \times 10^{5} /$ $\mathrm{kg}$ patient and $1 \times 10^{6} / \mathrm{kg}$ (Table 59.1). In the absence of GvHD, most groups have given prophylactic DLIs as single-shot intervention, but also repetitive DLIs are reported (Table 59.1; Tsirigotis et al. 2016; Jedlickova et al. 2016).

Table 59.1 Timing and dosing of prophylactic and preemptive DLI ${ }^{\mathrm{a}}$

\begin{tabular}{|c|c|c|c|c|}
\hline & Timing & Related & Unrelated & Haplo \\
\hline \multirow[t]{2}{*}{ Preemptive and prophylactic ${ }^{b}$} & 3 months & $1-5 \times 10^{5} / \mathrm{kg}$ & $1 \times 10^{5} / \mathrm{kg}$ & \\
\hline & 6 months & $1 \times 10^{6} / \mathrm{kg}$ & $1 \times 10^{6} / \mathrm{kg}$ & $1 \times 10^{4} / \mathrm{kg}$ \\
\hline Relapse in combination with chemotherapy ${ }^{c}$ & After chemotherapy & $1 \times 10^{7} / \mathrm{kg}$ & $1 \times 10^{7} / \mathrm{kg}$ & \\
\hline
\end{tabular}

Level C evidence

${ }^{a}$ A DLI can be repeated at 1-log higher 6-8 weeks after the first DLI, when, e.g., MRD is still present and no GVHD is observed. GVHD as endpoint of repetitive DLIs for preemptive DLIs is in the era of MRD monitoring no longer recommended

${ }^{\mathrm{b}}$ Tsirigotis et al. (2016)

${ }^{\mathrm{c}}$ Schmid et al. (2012) 


\subsubsection{Preemptive DLI}

DLIs are administered preemptively, i.e., in case of persistent MRD or when the first signs of relapse are observed, like MRD positivity or a decreasing donor chimerism. For persisting MRD, either the same initial cell dosages as for prophylactic DLI are used, followed by repetitive DLIs in 4-12 weeks' intervals, using an escalated dose schedule and increasing the cell dosages by five to tenfold at each infusion. Alternatively, five to tenfold higher initial cell doses are used in the preemptive situation as compared to prophylaxis. A total of three to four DLIs may be administered, and subsequent infusions are mostly taken from the same apheresis as the first but are frozen in the previously planned dosages. Occurrence of GVHD after DLI will result in no further DLI administration. For reappearance of MRD or mixed chimerism, obviously timing of DLI depends on the occurrence of these circumstances.

\subsubsection{Overt Relapses}

For overt relapses a combination of DLI with chemotherapy is mandatory (Schmid et al. 2012), and cell doses used in that situation are usually one order of magnitude higher than in the prophylactic or preemptive situation $\left(1 \times 10^{7} / \mathrm{kg}\right)$. In particular in acute leukemia, DLI alone may not be the preferred strategy for treatment of relapse. Repetitive DLIs can be considered after overt relapses based, e.g., on MRD positivity 6-8 weeks after DLI.

\subsubsection{Factors that May Influence Timing, Dosing, and Frequency of DLI}

\subsubsection{MRD}

Six weekly scheduled DLI with escalating doses until the first signs of GVHD as described above might no longer be necessary in the era of molecular disease monitoring. A MRD-driven strategy with more time between DLIs (8-12 weeks) might still allow for control of the hematological malignancy while avoiding long-term side effects like chronic GVHD. An alternative is the infusion of donor $\alpha \beta$ T cells engineered with a suicide gene. The thymidine kinase (TK) suicide gene has received conditional approval by EMA (Chabannon et al. 2018), and a novel safety switch (inducible caspase-9) characterized by lack of immunogenicity and rapid mechanism of action is under investigation (Zhou et al. 2014).

\subsubsection{Impact of Underlying Disease}

The different underlying diseases might require different doses, considering their sensitivity to a DLI-mediated GvL effect. The relapse workshop of the National Cancer Institute has proposed an estimate of the sensitivity of different diseases to DLI (Alyea et al. 2010). Accordingly, sensitivity is regarded as high for CML, myelofibrosis, and low-grade NHL; intermediate for AML, MDS, multiple myeloma, and Hodgkin's disease; and low for ALL and DLBCL.

\subsubsection{Donor Origin}

Dosage of DLI can under certain circumstances relate to the origin of the donor (Table 59.1). There is no consensus as to whether the dose between an unrelated and a related donor needs to differ. Similarly, cells doses in the haploidentical setting are unclear. More importantly and not well understood, but of greater impact, is most likely the processing of the DLI product with higher potency of freshly infused DLI when compared to frozen DLIs or DLIs used from the mobilized stem cell product due to different viabilities and compositions (Lemieux et al. 2016).

\subsubsection{Combination with Other Drugs}

DLIs are used in many diseases in combination with specific drugs targeting molecular aberrations of the underlying malignancy and/or acting via immune-modulating activities. However, the early administration of LENA after transplantation has been associated with a high incidence of GVHD (Kneppers et al. 2011), indicating that doses of DLI can also critically depend on the co-administration of drugs. Combinations with interferon- $\alpha$ and GM-CSF have also been reported as successful intervention to enhance the GVL effect (Dickinson et al. 2017). Other drugs currently explored are AZA, HDAC inhibitors (Bug et al. 2017), and Flt3- 
inhibiting TKI (Mathew et al. 2018), and dosage and timing of combined DLIs might be guided by the experience from prophylactic and preemptive DLIs but need to be carefully monitored.

\section{Key Points}

- DLIs are used prophylactically or as preemptive treatment of a persistent MRD.

- DLIs in combination with chemotherapy can be used to treat overt relapse after HSCT.

- Despite the wide use of DLI, it is challenging to provide specific guidelines for dosing and timing of DLIs, and there is no consensus on how to precisely administer them.

- Strict institutional guidelines and rigorous reporting on details of DLI like processing, timing, dosing, intervals, and combination with immune-modulating drugs are therefore needed, and the new cellular therapy registry of EBMT is designed to allow for analysis of daily practice and its impact on clinical outcome in years to come.

\section{References}

Admiraal R, Nierkens S, de Witte MA, et al. Association between anti-thymocyte globulin exposure and survival outcomes in adult unrelated haemopoietic cell transplantation: a multicentre, retrospective, pharmacodynamic cohort analysis. Lancet Haematol. 2017;4:e183-e91.

Alyea EP, DeAngelo DJ, Moldrem J, et al. NCI First International Workshop on the Biology, Prevention and Treatment of Relapse after Allogeneic Hematopoietic Cell Transplantation: report from the committee on prevention of relapse following allogeneic cell transplantation for hematologic malignancies. Biol Blood Marrow Transplant. 2010;16:1037-69.

Bleakley M, Heimfeld S, Loeb KR, et al. Outcomes of acute leukemia patients transplanted with naive $\mathrm{T}$ cell-depleted stem cell grafts. J Clin Invest. 2015;125:2677-89.

Boelens JJ, Admiraal R, Kuball J, Nierkens S. Fine-tuning antithymocyte globulin dosing and harmonizing clinical trial design. J Clin Oncol. 2018;36:1175-6.
Bug G, Burchert A, Wagner EM, et al. Phase I/II study of the deacetylase inhibitor panobinostat after allogeneic stem cell transplantation in patients with highrisk MDS or AML (PANOBEST trial). Leukemia. 2017;31:2523-5.

Chabannon C, Kuball J, Bondanza A, et al. Hematopoietic stem cell transplantation in its 60s: a platform for cellular therapies. Sci Trans1 Med. 2018;10:eaap9630.

Czerw T, Labopin M, Schmid C, et al. High CD3+ and CD34+ peripheral blood stem cell grafts content is associated with increased risk of graft-versus-host disease without beneficial effect on disease control after reduced-intensity conditioning allogeneic transplantation from matched unrelated donors for acute myeloid leukemia: an analysis from the Acute Leukemia Working Party of the European Society for Blood and Marrow Transplantation. Oncotarget. 2016;7:27255-66.

de Witte MA, Sarhan D, Davis Z, et al. Early reconstitution of NK and gammadelta T cells and its implication for the Design of Post-Transplant Immunotherapy. Biol Blood Marrow Transplant. 2018;24:1152-62.

Dickinson AM, Norden J, Li S, et al. Graft-versusleukemia effect following hematopoietic stem cell transplantation for leukemia. Front Immunol. 2017;8:496.

Handgretinger R, Schilbach K. The potential role of gammadelta $\mathrm{T}$ cells after allogeneic HCT for leukemia. Blood. 2018;131:1063-72.

Jedlickova Z, Schmid C, Koenecke C, et al. Long-term results of adjuvant donor lymphocyte transfusion in AML after allogeneic stem cell transplantation. Bone Marrow Transplant. 2016;51:663-7.

Kanakry CG, Coffey DG, Towlerton AM, et al. Origin and evolution of the $\mathrm{T}$ cell repertoire after posttransplantation cyclophosphamide. JCI Insight. 2016;1(5):e86252.

Kneppers E, van der Holt B, Kersten MJ, et al. Lenalidomide maintenance after nonmyeloablative allogeneic stem cell transplantation in multiple myeloma is not feasible: results of the HOVON 76 trial. Blood. 2011;118:2413-9.

Kolb HJ, Schmid C, Barrett AJ, Schendel DJ. Graftversus-leukemia reactions in allogeneic chimeras. Blood. 2004;103:767-76.

Lemieux J, Jobin C, Simard C, Neron S. A global look into human $\mathrm{T}$ cell subsets before and after cryopreservation using multiparametric flow cytometry and two-dimensional visualization analysis. J Immunol Methods. 2016;434:73-82.

Locatelli F, Merli P, Pagliara D, et al. Outcome of children with acute leukemia given HLA-haploidentical HSCT after alphabeta T-cell and B-cell depletion. Blood. 2017;130:677-85.

Malard F, Labopin M, Chevallier P, et al. Larger number of invariant natural killer T cells in PBSC allografts correlates with improved GVHD-free and progressionfree survival. Blood. 2016;127:1828-35.

Mathew NR, Baumgartner F, Braun L, et al. Sorafenib promotes graft-versus-leukemia activity in mice 
and humans through IL-15 production in FLT3ITD-mutant leukemia cells. Nat Med. 2018;24: 282-91.

Maury S, Lemoine FM, Hicheri Y, et al. CD4+CD25+ regulatory $\mathrm{T}$ cell depletion improves the graft-versustumor effect of donor lymphocytes after allogeneic hematopoietic stem cell transplantation. Sci Transl Med. 2010;2:41ra52.

Mielcarek M, Furlong T, O'Donnell PV, et al. Posttransplantation cyclophosphamide for prevention of graft-versus-host disease after HLAmatched mobilized blood cell transplantation. Blood. 2016;127:1502-8.

Orr MT, Lanier LL. Natural killer cell education and tolerance. Cell. 2010;142:847-56.

Pasquini MC, Devine S, Mendizabal A, et al. Comparative outcomes of donor graft CD34+ selection and immune suppressive therapy as graft-versus-host disease prophylaxis for patients with acute myeloid leukemia in complete remission undergoing HLA-matched sibling allogeneic hematopoietic cell transplantation. J Clin Oncol. 2012;30:3194-201.

Ravens S, Schultze-Florey C, Raha S, et al. Human gammadelta $\mathrm{T}$ cells are quickly reconstituted after stem-cell transplantation and show adaptive clonal expansion in response to viral infection. Nat Immunol. 2017;18:393-401.

Scheper W, van Dorp S, Kersting S, et al. GammadeltaT cells elicited by CMV reactivation after allo-SCT cross-recognize CMV and leukemia. Leukemia. 2013;27:1328-38.

Schmid C, Labopin M, Nagler A, et al. Treatment, risk factors, and outcome of adults with relapsed AML after reduced intensity conditioning for allogeneic stem cell transplantation. Blood. 2012;119:1599-606.

Stenger EO, Turnquist HR, Mapara MY, Thomson AW. Dendritic cells and regulation of graft-versushost disease and graft-versus-leukemia activity. Blood. 2012;119:5088-103.

Suessmuth Y, Mukherjee R, Watkins B, et al. CMV reactivation drives posttransplant T-cell reconstitution and results in defects in the underlying TCRbeta repertoire. Blood. 2015;125:3835-50.

Tsirigotis P, Byrne M, Schmid C, et al. Relapse of AML after hematopoietic stem cell transplantation: methods of monitoring and preventive strategies. A review from the ALWP of the EBMT. Bone Marrow Transplant. 2016;51:1431-8.

van Bergen CA, van Luxemburg-Heijs SA, de Wreede LC, et al. Selective graft-versus-leukemia depends on magnitude and diversity of the alloreactive $\mathrm{T}$ cell response. J Clin Invest. 2017;127:517-29.

van Heijst JW, Ceberio I, Lipuma LB, et al. Quantitative assessment of T cell repertoire recovery after hematopoietic stem cell transplantation. Nat Med. 2013;19:372-7.

Yew PY, Alachkar H, Yamaguchi R, et al. Quantitative characterization of $\mathrm{T}$-cell repertoire in allogeneic hematopoietic stem cell transplant recipients. Bone Marrow Transplant. 2015;50:1227-34.

Yun HD, Waller EK. Finding the sweet spot for donor lymphocyte infusions. Biol Blood Marrow Transplant. 2013;19:507-8.

Zhou X, Di Stasi A, Tey SK, et al. Long-term outcome after haploidentical stem cell transplant and infusion of $\mathrm{T}$ cells expressing the inducible caspase 9 safety transgene. Blood. 2014;123:3895-905.

Open Access This chapter is licensed under the terms of the Creative Commons Attribution 4.0 International License (http://creativecommons.org/licenses/by/4.0/), which permits use, sharing, adaptation, distribution and reproduction in any medium or format, as long as you give appropriate credit to the original author(s) and the source, provide a link to the Creative Commons license and indicate if changes were made.

The images or other third party material in this chapter are included in the chapter's Creative Commons license, unless indicated otherwise in a credit line to the material. If material is not included in the chapter's Creative Commons license and your intended use is not permitted by statutory regulation or exceeds the permitted use, you will need to obtain permission directly from the copyright holder.

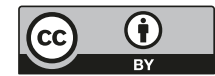

